\title{
Phytoconstituents of an ethanolic pod extract of Prosopis cineraria triggers the inhibition of HMG-CoA reductase and the regression of atherosclerotic plaque in hypercholesterolemic rabbits
}

\author{
Heera Ram ${ }^{1 *}$ (D, Noopur Jaipal ${ }^{1}$, Jaykaran Charan², Priya Kashyap ${ }^{3}$, Suresh Kumar ${ }^{3}$, Rashmi Tripathi", \\ Bhim Pratap Singh ${ }^{5}$, Chandra Nayaka Siddaiah', Abeer Hashem ${ }^{7,8}$, Baby Tabassum ${ }^{9}$ and Elsayed Fathi Abd_Allah ${ }^{10}$
}

\begin{abstract}
Background: The HMG-CoA reductase is key enzyme of cholesterol biosynthesis which potentially contributes in management of hypercholesterolemia. The present study was designed to assess the inhibitory effect of phytoconstituents of an ethanolic extract of Prosopis cineraria pods on HMG - CoA reductase and regression potential of atherosclerotic plaque.

Methods: Healthy, adult male, albino rabbits in which hypercholesterolemia was induced by supplying the high fat diet and a supplement of cholesterol powder with coconut oil (500 mg/5 ml/Day/kg body weight) for 15 days, were used as a disease model. Phytochemical analysis of an ethanolic extract Prosopis cineraria pods was conducted using LCMS, GCMS and FTIR analysis. Further, in-vitro, in-vivo and in-silico assessments were performed.

Results: The in-vitro assessment of HMG -CoA reductase activity indicated a 67.1 and $97.3 \%$ inhibition by the extract and a standard drug (Pravastatin), respectively. Additionally, an in-silico evaluation was made using appropriate docking software and results also indicated as significant interactions of the identified compounds with the target enzyme. Treatment of rabbits with the ethanolic extract of $P$. cineraria pod resulted in significant $(P \leq 0.001)$ reductions in total cholesterol, $L D L$ cholesterol, VLDL cholesterol, and triglyceride. Accordingly, reductions were occurred in atherosclerotic plaque, intima and media of aortal wall along with lumen volume of the aorta significantly increased $(P \leq 0.001)$.
\end{abstract}

Conclusion: It can be illustrating that the ethanolic extract of Prosopis cineraria pod contains potent bioactive phytocompounds might be inhibit HMG - CoA reductase and have regression potential of atherosclerotic plaque.

Keywords: HMG-CoA reductase, Hypercholesterolemia, Lipid profile, Antioxidants, Prosopis cineraria, Atherosclerosis

\section{Introduction}

Appropriate diets and dietary supplements have the potential for use in the management of various metabolic syndromes and their complications [1]. The fast food and/or junk food associated with many developed countries are having a drastic impact on the health of youth, as well as many adults with insufficient exercise. These types of food are typically rich in

\footnotetext{
* Correspondence: hr.zo@jnvu.edu.in; baradhr@gmail.com

'Department of Zoology, Jai Narain Vyas University, Jodhpur, Rajasthan 342001, India

Full list of author information is available at the end of the article
}

free fatty acids and contain a large amount of fatty substances, all of which promote diabetes, hypercholesterolemia, cancer, and other metabolic syndromes [2]. In fact, three metabolic syndromes, cardiovascular diseases, diabetes, and cancer are the cause of up to $60-70 \%$ of mortality, worldwide [3]. Hypercholesterolemia is an independent risk factor that alone or together with the consumption of unhealthy foods can accelerate the development of atherosclerosis and further resulted in atherosclerotic plaque [4]. An increased generation of intracellular free radicals has also been demonstrated

(c) The Author(s). 2020 Open Access This article is distributed under the terms of the Creative Commons Attribution 4.0 International License (http://creativecommons.org/licenses/by/4.0/), which permits unrestricted use, distribution, and 
to play an important role in chronic inflammatory responses and atherosclerosis.

Several pharmacological agents are available, however, to manage hypercholesterolemia and atherosclerosis. One of the most widely used agents used for the therapeutic treatment of atherosclerosis are HMG-CoA inhibitors, known as statins $[1,5]$. The long term use of statins, however, have been shown to be associated with undesirable side effects [6]. For this reason, there is increased interest to identify alternatives to the use of statins that are reliable, effective, and have no or a low-level of adverse effects. In this regard, herbal formulations have been the centre of focus. Studies have demonstrated that some plants and their products exhibit hypolipidemic potential [7].

For example, the desert plant, Prosopis cineraria, has been reported by several researchers to possess numerous medicinal properties, such as antidiabetic, hypoglycemic, anticancer, anti-inflammatory, antiasthmatic, as well as a myriad of other pharmaceutical properties $[8,9]$. Studies of this plant have also indicated that it possesses a number of potent bioactive compounds, including polyphenols, alkaloids, tannins, saponins, and flavonoids [10]. Notably, the pod of Prosopis cineraria is a key ingredient panchkuta, a local Indian food dish with proposed healthy attributes without side effects. Therefore, a study was conducted to evaluate the inhibitory effect of an ethanolic extract of Prosopis cineraria pods on HMG-CoA reductase, and the antioxidant and anti-atherosclerotic potential of the extract. In-vitro, in-vivo, and in-silico assessments of the extract were conducted.

\section{Materials and methods}

Pod procurement, authentication and extraction method Pods of Prosopis cineraria (commonly known as Sangari) were obtained from a local herbal shop and authenticated by an expert in botany. The dried pods were ground with a mortar and pestle and a 70\% ethanolic extract was obtained by soxhlation. A sticky extract was obtained and stored under desiccated conditions. Atorvastatin, a commonly prescribed statin, was purchased from a local pharmacy and used for comparative purposes (control). All chemicals were of reagent grade and purchased from Loba Chemie.

\section{LC/MS chemical analysis}

LC-MS based metabolomics is a methodology used for characterizing the chemical fingerprint of herbal plant extracts. In our analysis, several mobile phase sequences were analysed to obtain the most comprehensive elucidation of chromatographic peaks [11].
Gas chromatography with tandem mass spectrometry (GC-MS/MS) analysis

GC-MS analysis of the ethanol pod extract of Prosopis cineraria was conducted using a standard protocol. The sample was injected into a gas chromatograph interfaced with a mass spectrometer (GC-MS) [12].

\section{FTIR analysis}

An FTIR Spectrophotometer (Bruker Co., Germany) equipped with a standard detector and a germanium beam splitter, which was interfaced to a computer and analytical software, was utilized for the analysis. The $\mathrm{KBr}$ pellet technique was used to obtain a spectrum was in the mid IR region of $400-4000 \mathrm{~cm}^{-1}$. The spectrum was characterized using the attenuated Total Reflectance (ATR) technique [13].

\section{In-vitro assessment of HMG -CoA reductase inhibition}

The inhibitory effect of the plant extract on HMG-CoA activity in vitro was determined using an HMG-CoA reductase assay kit (Sigma-Aldrich), which is based on a spectrometric measurement. The concentration of a standard HMG-CoA reductase stock solution was $0.50-0.70 \mathrm{nM}$. Different concentrations $(5 \mu \mathrm{g} / \mathrm{ml}, 2.5 \mu \mathrm{g} / \mathrm{ml}, 1.25 \mu \mathrm{g} / \mathrm{ml}, 0.62 \mu \mathrm{g} / \mathrm{ml}$, and $0.32 \mu \mathrm{g} / \mathrm{ml}$ ) of the ethanolic extract were mixed with a reaction mixture containing NADPH, HMG-CoA substrate, and HMGR. Pravastatin (Sigma Aldrich co.) was used as a positive control and distilled water served as a negative control $[12,14]$. Inhibition activity was calculated according to the following equation.

$$
\text { Units } / m g P=\frac{\left(\Delta A_{340} / m^{2} \text { sample }_{\text {s }}-\Delta A_{340} / \text { min }_{\text {blank }}\right) \times T V}{12.44 \times V \times 0.6 \times L P}
$$

Where:

12.44 $=\varepsilon m M$ - the extinction coefficient for NADPH at $340 \mathrm{~nm}$ is $6.22 \mathrm{mM}-1 \mathrm{~cm}-1.12 .44$ represents the 2 NADPH molecules consumed in the reaction.

$\mathbf{T V}=$ Total volume of the reaction in $\mathrm{ml}(1 \mathrm{ml}$ for cuvettes and $0.2 \mathrm{ml}$ for plates)

$\mathbf{V}=$ Volume of enzyme used in the assay $(\mathrm{ml})$

$\mathbf{0 . 6}=$ Enzyme concentration in mg-protein (0.50-0.70

$\mathrm{mg} \mathrm{P} / \mathrm{ml}$ )

$\mathbf{L P}=$ Light path in $\mathrm{cm}$ (1 for cuvettes and 0.55 for plates).

\section{Induction of hypercholesterolemia in rabbits and the experimental design}

New Zealand, white, male rabbits, weighing approximately $1.5 \pm 0.2 \mathrm{~kg}$, were used as an animal model. They were acclimatized for 10 days in cages under controlled environmental conditions consisting of a 12-h light/dark regime 
and a temperature of $23 \pm 2{ }^{\circ} \mathrm{C}$. Food was supplemented with green leafy, seasonal vegetables and water. Hypercholesterolemia was induced by oral administration of $500 \mathrm{~g}$ of cholesterol powder mixed with $5 \mathrm{ml}$ of coconut oil for 15 days along with a high fat diet [15].

Animals were divided into four groups $(n=5)$ and the experimentation period was 60 days.

Group 1: Control, treated with only distilled water for 60 days.

Group 2: Hypercholesterolemic diet for 60 days.

Group 3: Treatment with ethanolic $P$. cineraria pod extract $(400 \mathrm{mg} / \mathrm{kg} /$ day) for 45 days after induction of hypercholesterolemia for 15 days.

Group 4: Treatment with atorvastatin $(0.25 \mathrm{mg} / \mathrm{kg})$ for 45 days after induction of hypercholesterolemia for 15 days.

\section{Samples collections of in-vivo studies and planimetric} study

After completion of the experiment at 60 days, overnight fasting animals were autopsied under mild anaesthesia. Blood samples were collected directly via a cardiac puncture and kept in both EDTA-coated test tubes and normal tubes for biochemical and hematological assessments, respectively. The vital organs (heart, aorta, kidney, and liver) were removed, fixed in formalin. and processed for histopathological examination. Planimetric studies of the aorta wall, lumen volume and atherosclerotic plaque were conducted using a Camera Lucida [15].

\section{Biochemical analyses}

Serum was separated by centrifugation and stored at $-20^{\circ} \mathrm{C}$. After thawing, assessments of total cholesterol

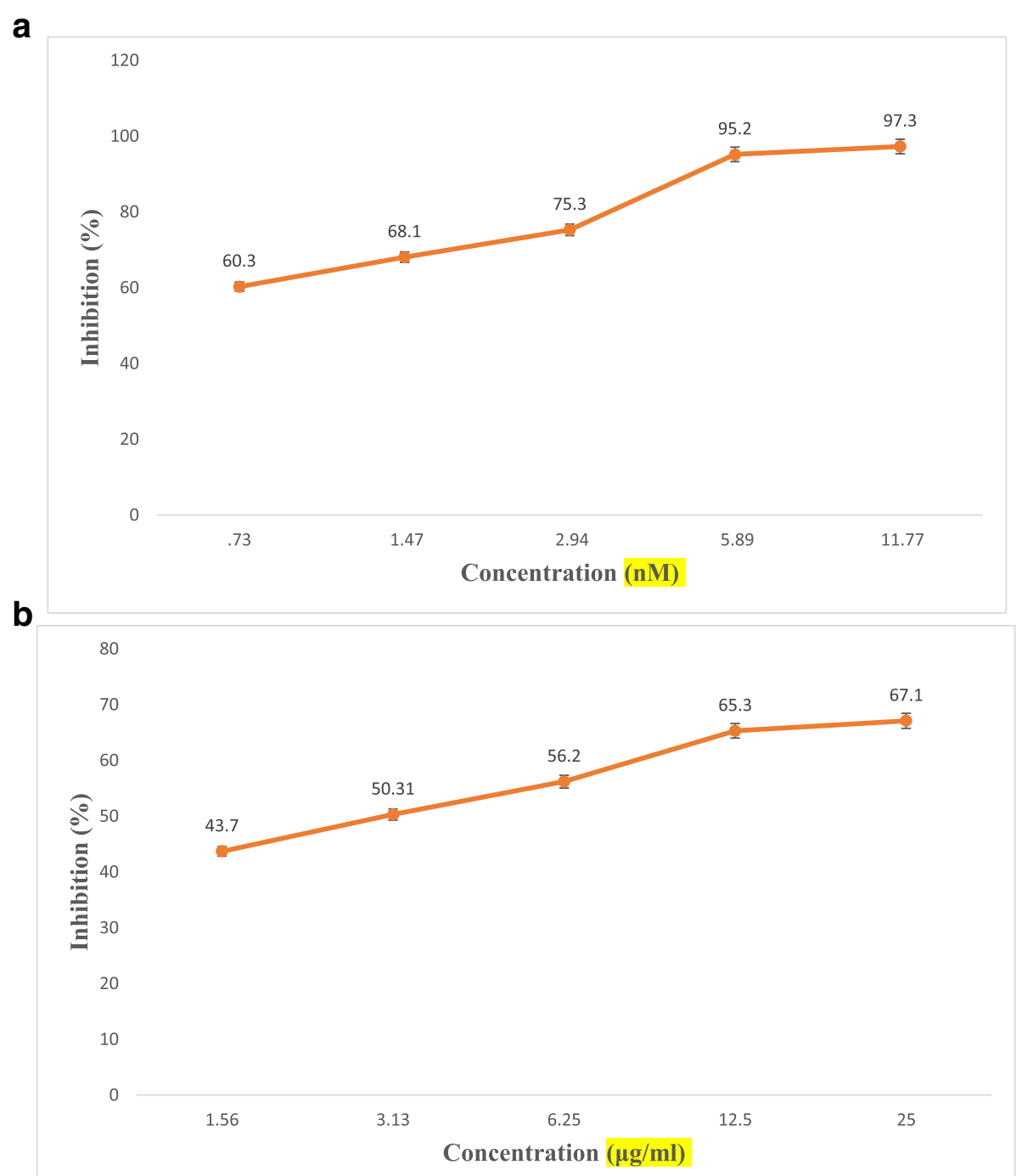

Fig. 1 a HMG - CoA reductase Inhibition potential of Pravastatin. b HMG - CoA reductase Inhibition potential of ethanolic pod extract of Prosopis cineraria 
[16], triglyceride [17], HDL - cholesterol [18], lipid profile [19], glucose [20], and other significant parameters were determined using standard methods.

\section{Assessment of antioxidant properties}

Serum LPO (lipid peroxidation) was determined by measuring thiobarbituric acid reactive substances (TBARS) and expressed as malondialdehyde (MDA) content, following the method of Ohkawa [21]. Catalase and superoxide dismutase activity were assessed using the Aebi and Markland methods, respectively [22].

\section{Molecular docking}

Molecular docking of HMG-CoA reductase (PDB:1DQ9) with Pravastatin (Standard Drug, Pubchem CID: 16759173) and the dominant phytocompounds in the ethanolic extract, i.e. Prosopilosine (Pubchem CID: 45269734), Prosogerin A (Pubchem CID: 44257586), Cinerin C (Pubchem CID: 101485482), $\beta$ - Sitosterol (Pubchem CID: 222284), and Gallic Acid (Pubchem CID: 370) were conducted using Autodock 4.2. Water molecule and other co-factors were removed from the
Table 1 Identified phytocompounds of pod extract of $P$. cineraria by UPLC-QTOF analysis

\begin{tabular}{llll}
\hline S. No. & Identified compound & Monoisotopic mass & Retention time (min) \\
\hline 1 & Cinnerin C & 402.168 & 14.5 \\
2 & Prosopilosine & 629.586 & 12.2 \\
3 & Prosogerin A & 312.063 & 13.2 \\
4 & B- Sitosterol & 412.371 & 12.9 \\
5 & Gallic Acid & 170.022 & 6.9 \\
\hline
\end{tabular}

target molecule, while hydrogen atoms were added. Ligand was also prepared and docked into the active/ binding site of the target molecule [23].

\section{Statistical analysis}

Results of the biochemical assessments, organs weights, and planimetric studies are expressed as a mean \pm standard error of the mean (SEM) and statistical differences were determined by ANOVA and post hoc mean separation tests.

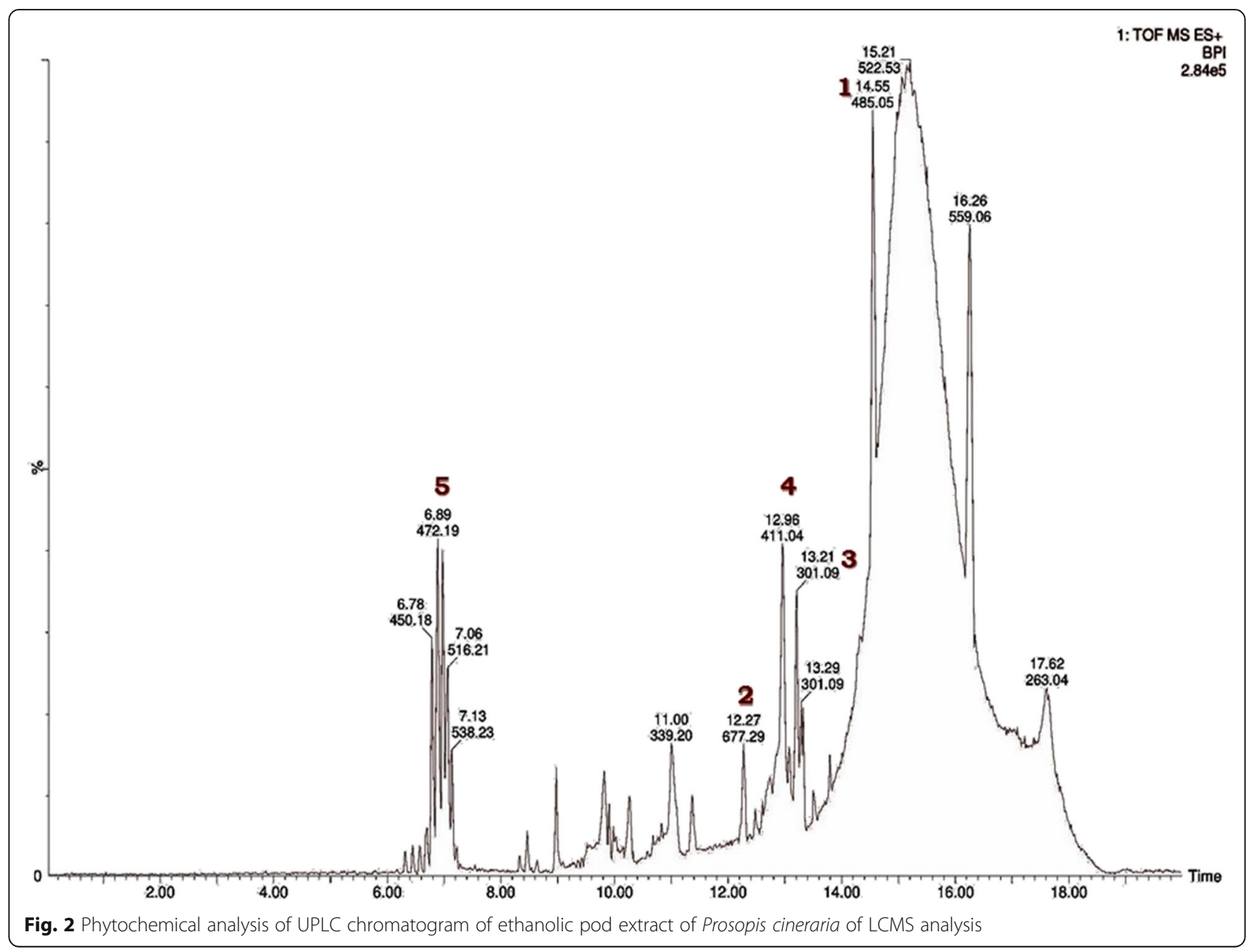


Table 2 Identified phytocompounds of pod extract of $P$. cineraria by GC/MS analysis

\begin{tabular}{llcc}
\hline S. No. & $\begin{array}{l}\text { Identified } \\
\text { compound }\end{array}$ & $\begin{array}{l}\text { Monoisotopic } \\
\text { mass }\end{array}$ & $\begin{array}{c}\text { Retention } \\
\text { time (min) }\end{array}$ \\
\hline 1 & 3-O-Methyl-D-Glucose & 2923 & 17.419 \\
\hline
\end{tabular}

\section{Results}

\section{In-vitro HMG-CoA reductase inhibition assay}

The different concentrations of plant extract and the standard inhibitor exhibited a 67.1 and $97.5 \%$ level of inhibition of HMG-CoA activity, respectively, as indicated by the product rate per minute, were calculated using the described formula (Figs. 1a and b).

\section{LC-MS, GC-MS, and FTIR spectroscopy phytochemical analysis}

Using data from the literature and METLIN software, the masses of the constituents were identified based on the monoisotopic mass of the alleged compounds as $M$ and $\mathrm{M}+\mathrm{H}$ ion using QTOF mass hunter software. The default range for mass documentation was kept above a $100 \mathrm{~m} / \mathrm{z}$ ratio. The mass spectra exhibited five major peaks in the pod extract (Table 1 and Fig. 2). The GC/MS data also revealed the presence of 3-O-Methyl-D-Glucose (Table 2 \& Fig. 3). The functional groups of phytoconstituents in the mid IR region of a $400-4000 \mathrm{~cm}^{-1}$ wave length were also annotated (Table 3 and Fig. 4).

\section{Lipid profile}

The treatment of rabbits with the ethanolic extract of Prosopis cineraria pods resulted in significant reductions in total cholesterol, LDL-cholesterol, triglyceride, VLDL relative to the other treatment groups (Table 4).

\section{Effect on antioxidant status}

The MDA content, which is an indicator of lipid peroxidation, was significantly higher $(P \leq 0.001)$ in the hypercholesterolemic group compared to the control group (distilled water). However, a significant reduction in MDA content was observed in the rabbits treated with the ethanolic extract. A significant increase $(\mathrm{P} \leq 0.001)$ in serum SOD and catalase was also observed in the group of hypercholesterolemic rabbits treated with the ethanolic plant extract, relative to the untreated group of hypercholesterolemic rabbits. (Fig. 5).

\section{Histopathology}

The histological analysis of the aorta revealed three layers, i.e. intima, media, and adventitia, with enlarged lumen volume in the control group (Fig. 6a). In contrast, a bulging structure of atherosclerotic plaque, and reduced thickened media and lumen volume was observed in the aorta of the hypercholesterolemic rabbits (Fig. 6b). Treatment of hypercholesterolemic rabbits with either Prosopis cineraria pod extract or atorvastatin resulted in a significant reduction in atherosclerotic plaque and an increase in lumen volume; as well as reconstituted layer thickness of the intima, media, and adventitia layers (Fig. 6c and d).

\section{Planimetric study}

Fatty plaque with foam cells were seen within the intima region of the aorta of hypercholesterolemic rabbits. In contrast, a significant regression in aortic plaque up to $73.55 \%$ along with increased lumen volume up to $23.46 \%$ and a somewhat normal histoarchitecture was observed in rabbits treated with the treatment of ethanolic extract of Prosopis cineraria pods, compared to the control and standard drug treated groups of rabbits (Table 5).

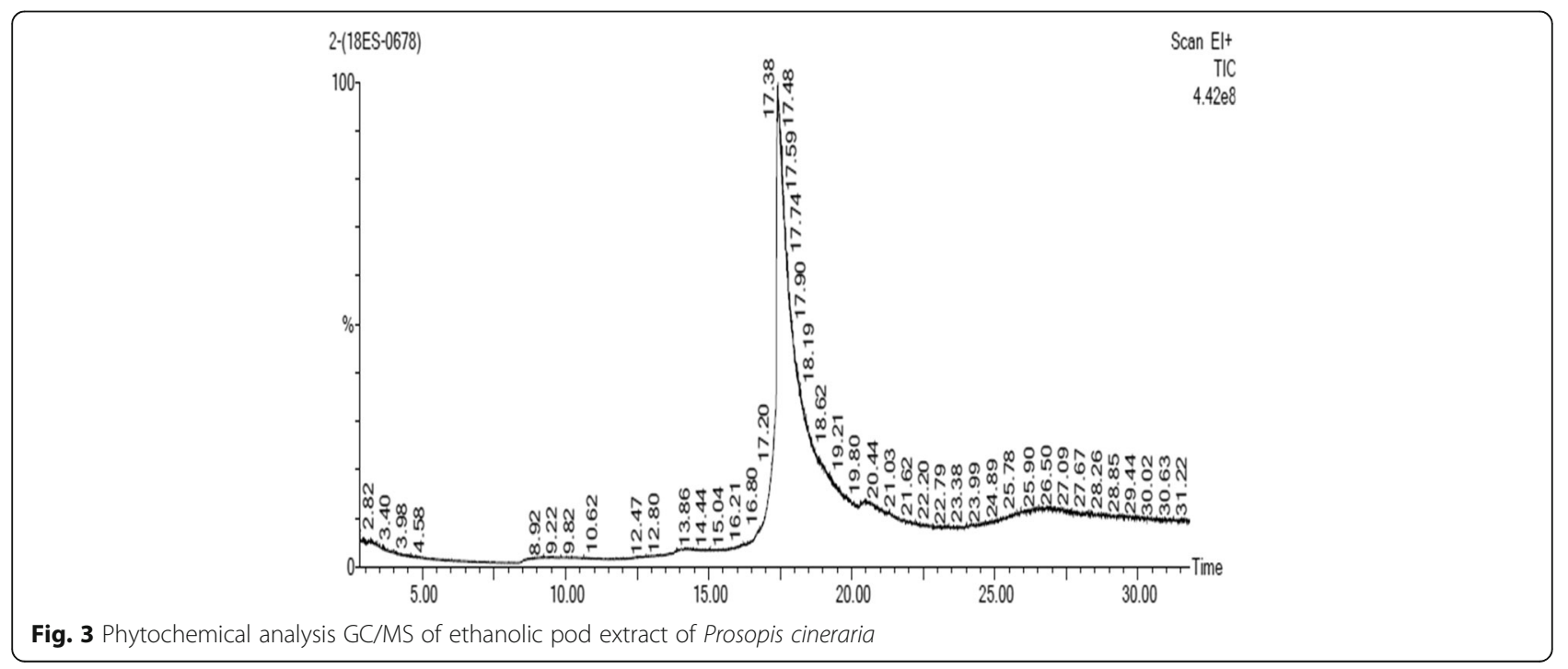


Table 3 FTIR - analysis of ethanolic pod extract of Prosopis

\begin{tabular}{lll} 
Cineraria & & \\
\hline S. No & Wavelength & Functional group \\
\hline 1. & 3163.08 & $\mathrm{CH}, \mathrm{NH}$ \\
2. & 3020.30 & $\mathrm{CH}$ \\
3. & 2935.91 & $\mathrm{CH}$ \\
4. & 2876.19 & $=\mathrm{CH} 3$ \\
5. & 1715.41 & $\mathrm{C}=\mathrm{O}$ (carbonyl group) \\
6. & 1616.00 & $\mathrm{C}=\mathrm{C}$ \\
7. & 1355.44 & Nitro \\
8. & 1224.06 & $\mathrm{C}-\mathrm{O}$ \\
9. & 1128.73 & $\mathrm{C}-\mathrm{O}$ \\
10. & 1028.13 & Alkyl halides(R-Cl) \\
11. & 910.97 & Alkenes \\
12. & 846.69 & Alkyl halides (R-Cl) \\
13. & 735.35 & Aromatic compounds \\
14. & 643.05 & Alkyl halides \\
\hline
\end{tabular}

\section{Molecular docking}

The molecular docking of HMG-CoA reductase with ligands (standard drug and phytoconstituents of the plant extract) exhibited significant affinity and molecular interactions with the target protein as indicated by the binding energy, number of $\mathrm{H}$-bonds and bond lengths (Table 6 and Fig. 7a-e).

\section{Discussion}

Dietary approaches are frequently used for managing health problems, with specific diets being recommended for the therapeutic treatment of various ailments [24]. Historical treatments are chiefly based on herbal formulations with their efficacy being dependent on the presence of active compounds within the herbal preparation and their bioreactivity [24, 25]. In contrast, improper diet is often the cause of several metabolic disorders and their resulting complications. In modern times, junk food and a fat rich diet have received considerable attention due to their role as a principle factor in hypercholesterolemia and obesity [26]. In the present study, similar symptoms of these atherosclerosis were observed in healthy rabbits after they were subjected to oral administration of cholesterol supplements and a high fat diet. Hypercholesterolemia may result through various mechanisms which results in the progression of atherosclerosis in animal models and higher primates [27-29]. Atherosclerosis is now considered the principle reason for mortality and morbidity worldwide [30]. Numerous therapies presently exist to combat atherosclerosis, such as statins which are HMG-CoA reductase inhibitors, bile acid sequestrants, fibrates, and niacin; all of which are designed to improve the lipid profile [5]. However, these therapeutic agents are often associated with undesirable side effects. In particular, statins are an efficient therapy for treating hypercholesterolemia, through their ability to reduce cholesterol biosynthesis by targeting HMG-Co

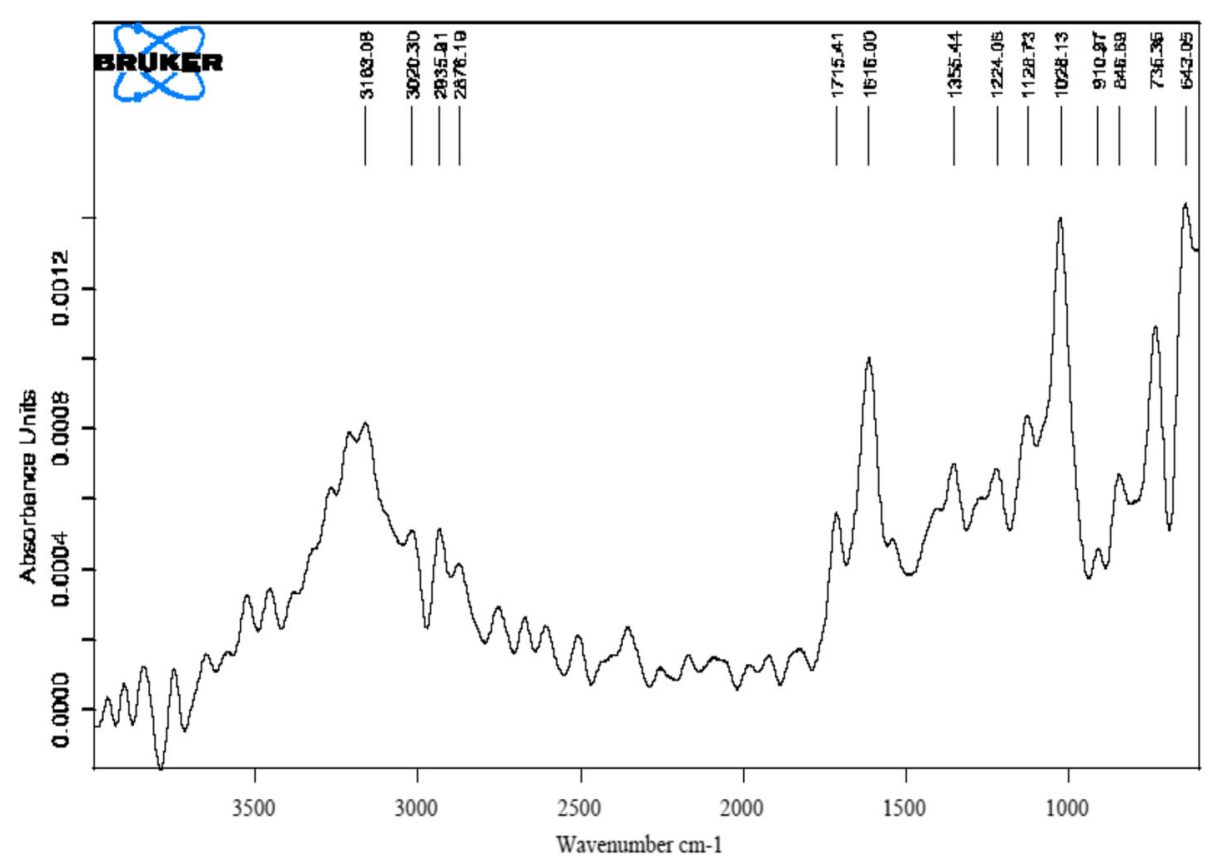

Fig. 4 Phytochemical analysis by FTIR of ethanolic pod extract of Prosopis cineraria 
Table 4 Lipid Profile of ethanolic pod extract of Prosopis cineraria treatment

\begin{tabular}{llllll}
\hline Treatment group & $\begin{array}{l}\text { Total cholesterol } \\
(\mathrm{mg} / \mathrm{dl})\end{array}$ & $\begin{array}{l}\text { HDL cholesterol } \\
(\mathrm{mg} / \mathrm{dl})\end{array}$ & $\begin{array}{l}\text { LDL Cholesterol } \\
(\mathrm{mg} / \mathrm{dl})\end{array}$ & $\begin{array}{l}\text { VLDL Cholesterol } \\
(\mathrm{mg} / \mathrm{dl})\end{array}$ & $\begin{array}{l}\text { Triglycerides } \\
(\mathrm{mg} / \mathrm{dl})\end{array}$ \\
\hline Control (Gr.1) & $59.5 \pm 2.11$ & $21.03 \pm 2.9$ & $20.69 \pm 1.57$ & $17.78 \pm 1.06$ & $69.87 \pm 2.05$ \\
Hypercholesterolemic (Gr.2) & $1216.5 \pm 49.3^{c}$ & $167.15 \pm 8.55^{c}$ & $1022 \pm 66.41^{c}$ & $26.54 \pm 8.56^{c}$ & $84.7 \pm 5.2^{c}$ \\
Ethanolic pod extract of P. cineraria (Gr.3) & $67.01 \pm 4.9^{c, g}$ & $20.15 \pm 2.5^{c, g}$ & $21.65 \pm 2.1^{c, g}$ & $24.77 \pm 1.5^{c, g}$ & $94.5^{c} \pm 11.57^{c, g}$ \\
Atorvastatin (Gr.4) & $80.80 \pm 4.9^{c, g}$ & $15.77 \pm 1.75^{c, g}$ & $46.24 \pm 7.8^{c, g}$ & $18.74 \pm 4.42^{c, g}$ & $74.13 \pm 2.5^{c, g}$ \\
\hline
\end{tabular}

Data are means \pm S.E.M. $(n=8) ; a, P \leq 0.05$ and $c, P \leq 0.001$ as compared to the respective control values and $g, P \leq 0.001$ as compared to the respective values of the Chol diet fed group

reductase activity; which is a rate limiting enzyme in the melvonate pathway [31]. The long-term use of statins, however, can result in severe adverse side effects. In contrast, nutraceuticals often exhibit little to no side effects and have been used in the treatment of atherosclerosis, hypercholesterolemia, and various other ailments [32].

In this regard, the desert region of western Rajasthan, India has a native plant, Prosopis cineraria, whose pods are used to make an herbal extract which is rich in potent phytochemicals $[8,9]$. Bark tissues of Prosopis cineraria already have been previously demonstrated to have anti-atherosclerotic activity $[8,33]$. In the present study, treatment of hypercholesterolemic rabbits with an ethanolic extract of Prosopis cineraria pods resulted in a significant reduction in plaque formation, as well as improvements in their lipid profiles. These results were similar to the those obtained by Ram and co-workers who demonstrated the anti-atherosclerotic activity of Prosopis cineraria and Acacia senegal bark extracts [15, 33]. It is plausible that these results are due to the presence of potent anti-atherosclerotic and hypocholesterolemic phytoconstituents that reduce lipids and necrotic material, support endothelial repair, or halt the proliferation of vascular smooth muscle cells [34-36]. Several mechanisms may be responsible for this therapeutic activity, such as a reduction in high-density lipoprotein cholesterol (HDL-C), destruction of foam cells and macrophages in lymph nodes, and the restoration of the endothelium by neighbouring cells or circulating progenitors $[32,37]$. The alteration in the lipid profile and the regression of atherosclerotic plaque by the plant extract was supported by results obtained in the invitro HMG-CoA reductase inhibition assay and in-silico evaluation conducted in previous studies [38, 39]. The phytoconstituents in the extract were analysed and identified by LCMS, GCMS, and FTIR; which validated the existence of several phytoconstituents identified functional groups that could potentially interact with target enzyme and serve as competitive inhibitors or analogues of substrates [37, 38, 40].

Additionally, oxidative stress and the production of free radicals have been shown to induce degenerative changes that promote endothelial dysfunction and are

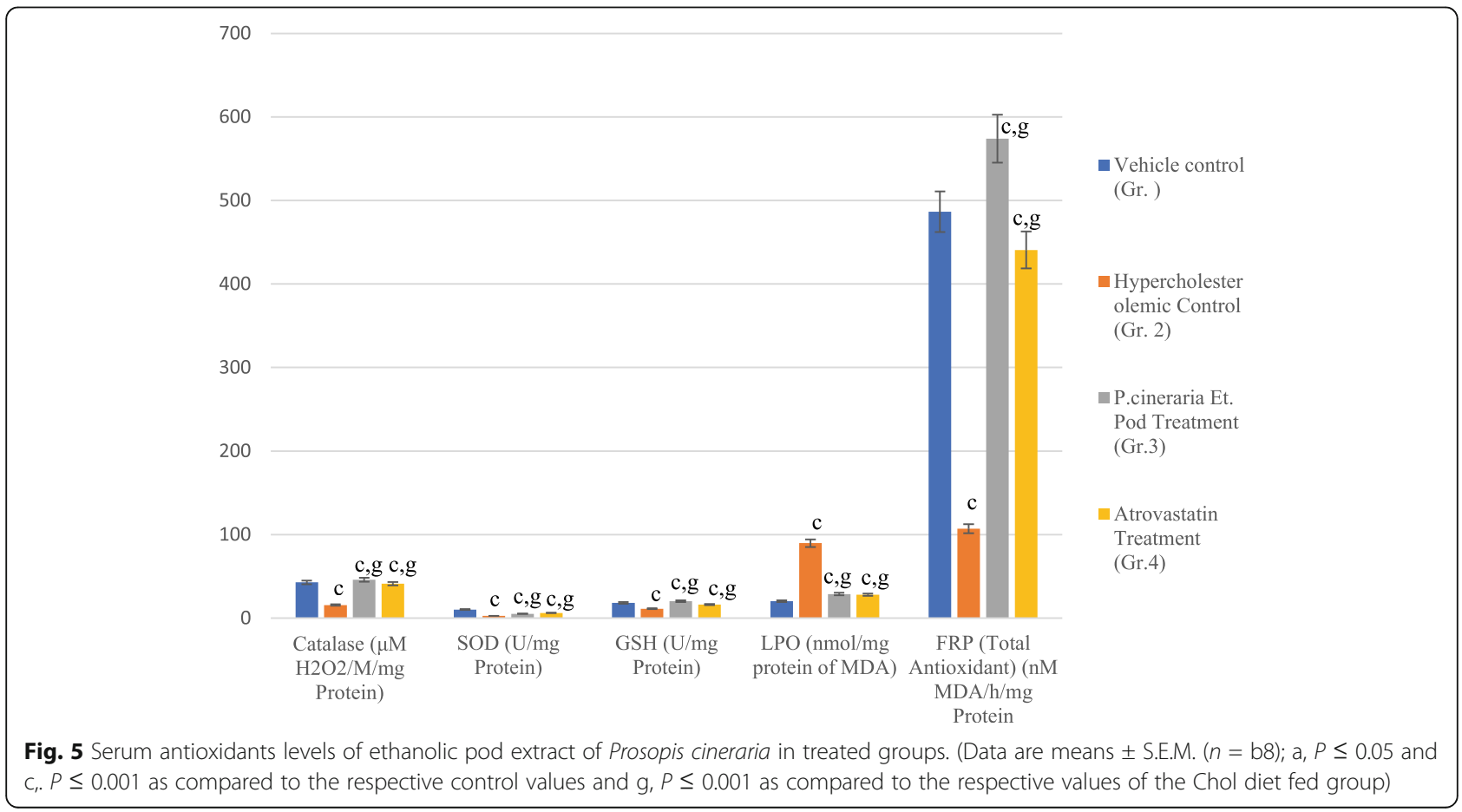




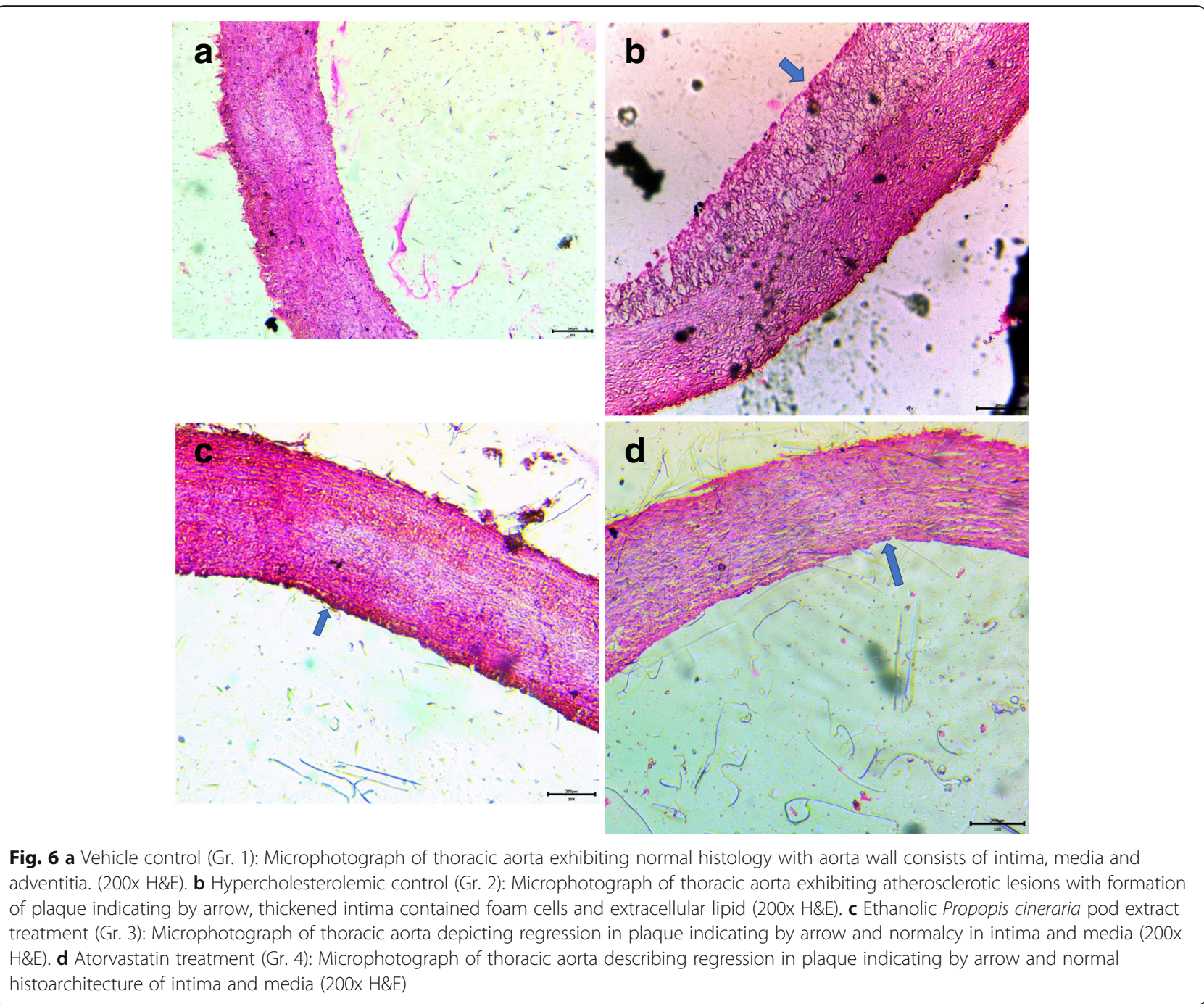

thus involved in the pathogenesis of atherosclerosis and are also linked to other metabolic syndromes $[41,42]$. In the present study, treatment of rabbits with the ethanolic extract increased antioxidant levels; including SOD and catalase activity. The reduction in oxidative stress and the general increase in antioxidant levels may be attributed to the presence of antioxidants in the plant extract and the ability of the phytoconstituents to generally boost the antioxidant system. Several studies have indicated that oxidation-reduction reactions play a vital role in atherogenesis; however, analysing the role of antioxidants only with respect to their reduction potential may be too narrow of a perspective. Park et al., (2015) reported that the $\alpha$-asarone constituent in plant extracts of $\mathrm{Pe}$ rilla frutescens extracts exhibit a strong antioxidant capacity and avert the oxidation of LDL in vitro and in vivo [43]. Additionally, the $\alpha$-asarone also triggered the macrophage response to LXR and PPAR- $\gamma$ agonists, by decreasing SR-B1 and increasing the interaction with ABCA-1 and ABCG-1.

Table 5 Planimetric Dimensions of Ascending Aorta of ethanolic pod Extract of Prosopis cineraria Treated Intact Rabbits (Mean of 5 Values \pm SEM)

\begin{tabular}{llll}
\hline Treatment Groups & Total Wall Area & Lumen & Plaque \\
\hline Control (Gr.1) & $49.42 \pm 1.99$ & $50.74 \pm 1.44$ & Nil \\
Hypercholesterolemic (Gr.2) & $78.16 \pm 3.61^{c}$ & $32.21 \pm 2.52^{c}$ & $18.59 \pm 1.01^{c}$ \\
Ethanolic pod extract of P. cineraria (Gr.3) & $57.21 \pm 5.01^{c}$ & $44.11 \pm 3.23^{c, g}$ & $4.89 \pm 1.38^{c, g}$ \\
Atorvastatin (Gr.4) & $53.29 \pm 1.01^{c, g}$ & $49.31 \pm 2.44^{c, g}$ & $1.31 \pm 0.02^{c, g}$
\end{tabular}

Data are means \pm S.E.M. $(n=5) ; \mathrm{a} P \leq 0.05 ; \mathrm{b} P \leq 0.01 ; \mathrm{c} P \leq 0.001$; and $\mathrm{d}$ nonsignificant as compared to the respective control values. $\mathrm{g} P \leq 0.001$ and $\mathrm{h}$ nonsignificant as compared to the respective values of the Chol diet fed group 
Table 6 HMG -CoA reductase molecular docking with standard drugs and phytoconstituents of ethanolic pod extract of Prosopis cineraria

\begin{tabular}{|c|c|c|c|c|}
\hline $\begin{array}{l}\text { S. } \\
\text { No. }\end{array}$ & Ligand & $\begin{array}{l}\text { Binding Energy (Kcal/ } \\
\text { mol) }\end{array}$ & $\begin{array}{l}\text { No. of } \mathrm{H}- \\
\text { bonds }\end{array}$ & RMSD \\
\hline \multicolumn{5}{|c|}{ Positive control } \\
\hline 1. & Pravastatin & -7.0 & 2 & 1.8 \\
\hline 2. & Atorvastatin & -7.5 & 2 & 2.4 \\
\hline \multicolumn{5}{|c|}{ Phytoconstituents } \\
\hline 3. & Cinnerin C & -6.5 & 1 & 1.3 \\
\hline 4. & Prosogerin A & -7.9 & 2 & 1.4 \\
\hline 5. & Gallic Acid & -6.2 & 2 & 0 \\
\hline 6. & $\begin{array}{l}\text { Beta- } \\
\text { sitosterol }\end{array}$ & -6.8 & 1 & 1.9 \\
\hline
\end{tabular}

Thus, the efficacy of $\alpha$-asarone could be attributed to both its antioxidant potential and its effect on lipid metabolism [44]. It appears that a balance between oxidative stress and antioxidants is needed in the therapeutics used to treat metabolic syndromes. The antioxidant defense system in cells includes catalase, SOD, and GPx, which help in the degradation of NO [45]. Hypercholesterolemia leads to a decrease in SOD and catalase levels [46]. In the present study, treatment of rabbits with an ethanolic extract of $P$. cineraria pods resulted in a significant elevation in catalase and SOD levels, which may have been induced by the free radical scavenging activity properties of the phytoconstituents present in the plant extract. Our results also indicated that LPO (lipid peroxidation) was reduced in rabbits treated with the extract; which again confirms its role in scavenging reactive oxygen species (ROS). It is possible that these effects may be directly due to the free radical scavenging potential of the phytoconstituents in the ethanolic extract [47]. Collectively, results of the present study demonstrate that the phytoconstituents contained in an ethanolic extract of Prosopis cineraria pods inhibits HMG - CoA reductase activity and reduces the level of atherosclerotic plaque in hypercholesterolemic rabbits.

\section{Conclusion}

This present study demonstrated that an ethanolic extract of Prosopis cineraria pods can reduce serum cholesterol when fed to hypercholesterolemic rabbits. The extract also reduced the level of atheromatous plague in
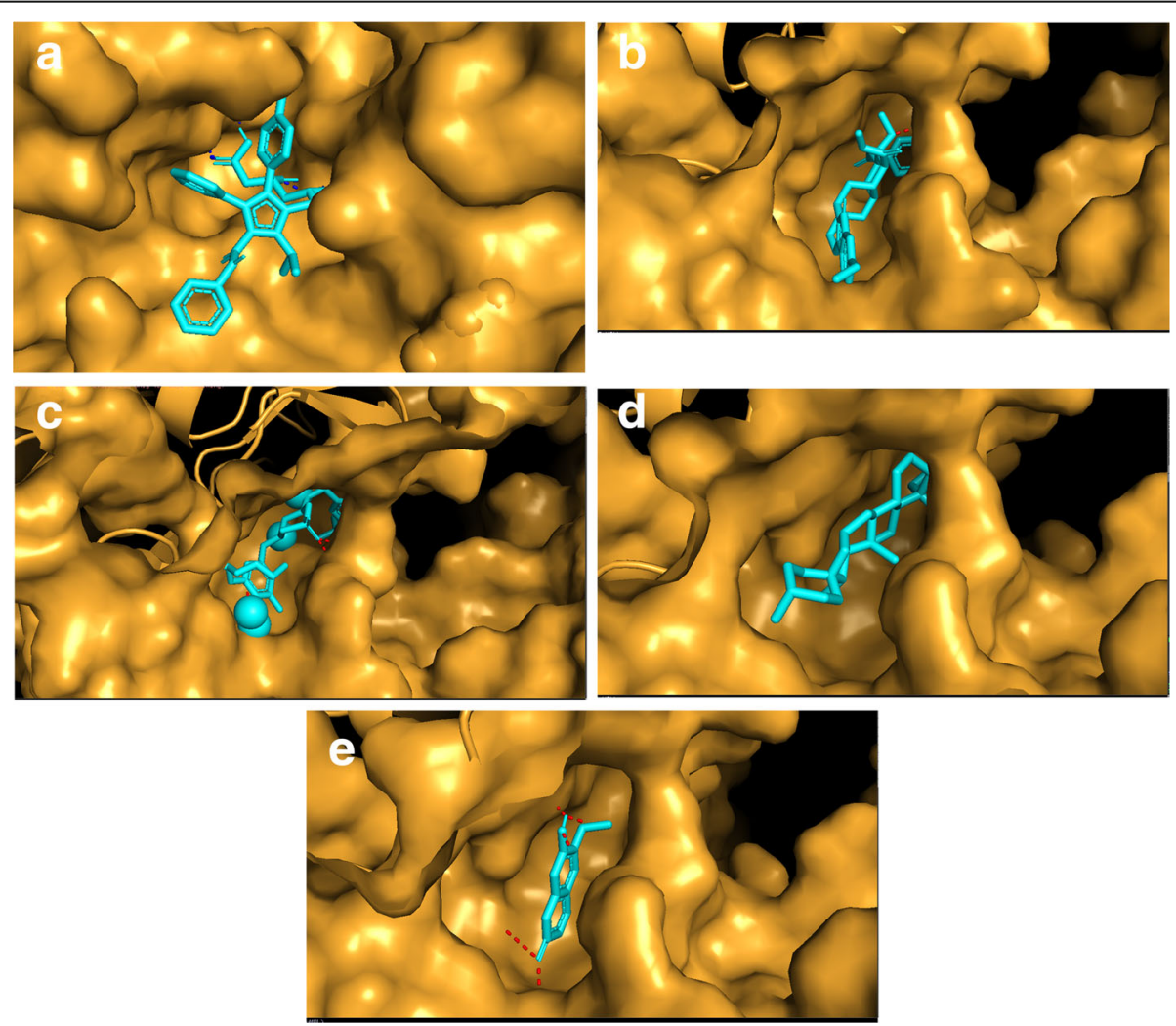

Fig. 7 a Interaction of Atorvastatin with target enzyme HMG - CoA reductase. b Interaction of Pravastatin with target enzyme HMG - CoA reductase. c Interaction of Prosogerin - A with target enzyme HMG - CoA reductase. $\mathbf{d}$ Interaction of Prosopilosine with target enzyme HMG - CoA reductase. e Interaction of $\beta$-sitosterol with target enzyme HMG - CoA reductase 
the aorta. Notably, the extract can improve antioxidant enzyme activity and inhibits HMG-Co reductase activity. Therefore, the use of an ethanolic extract of Prosopis cineraria pods should be further investigated as an alternative therapeutic agent to statins and other drugs, but one that does not have adverse side effects for the treatment of cardiovascular diseases.

\section{Abbreviations}

CPCSEA: Committee for the Purpose of Control and Supervision of Experiments on Animals; FRAP: Ferric reducing antioxidant potential; FTIR: Fourier-transform infrared spectroscopy; GCMS: Gas chromatographymass spectrometry; GSH: Glutathione Sulfhydryl (Reduced Glutathione); HDL: High density lipoprotein; HMG-CoA Reductase: 3-hydroxy-3methylglutaryl-coenzyme A reductase; IAEC: Institutional Animal Ethical Committee; LCMS: Liquid chromatography-mass spectrometry; LDL: Low density lipoprotein; LPO: Lipid peroxidation; QTOF MS: Quadrupole time-offlight mass spectrometry; SGOT: Serum glutamic oxaloacetic transaminase; SGPT: Serum glutamic pyruvic transaminase; SOD: Superoxide dismutase; TBARS: Thiobarbituric acid reactive substances; VLDL: Very low-density lipoprotein

\section{Acknowledgments}

We would like to acknowledge the kind co-operation of AllMS, Jodhpur for the HMG-CoA reductase inhibition assay and the Department of Zoology for providing essential support for this study. The authors would like to extend their sincere appreciation to the Researchers Supporting Project Number (RSP-2019/134), King Saud University, Riyadh, Saudi Arabia.

\section{Authors' contributions}

$\mathrm{HR}, J K C, S K, B P S, E F A-$ Experimental design, planning of work and review the manuscript; NJ - Experimentations; PK-In -silico analysis; RT- FTIR analysis; CNS- GCMS analysis; AH-Review the Manuscript; BT-Review the manuscript. All authors read and approved the final manuscript.

\section{Availability of data and materials}

All data produced during this study are incorporated in this article.

\section{Ethical approval and consent to participate}

The experimental design and protocols of treatments of the animals was approved by the Institutional Animal Ethics Committee (IAEC) which is registered under CPCSEA (Reg. No.1646/GO/a/12/CPCSEA valid up to 27.03.23).

\section{Consent for publication}

Not applicable.

\section{Competing interests}

The authors declare that they have no competing interests.

\section{Author details}

'Department of Zoology, Jai Narain Vyas University, Jodhpur, Rajasthan 342001, India. ${ }^{2}$ Department of Pharmacology, All India Institute of Medical Sciences, Jodhpur, Rajasthan 342001, India. ${ }^{3}$ UniversitySchool of Biotechnology, GGS Indraprastha University, Dwarka, Sector 16C, New Delhi 110075, India. ${ }^{4}$ Department of Bioscience and Biotechnology, Banasthali University, Banasthali, Rajasthan 304022, India. ${ }^{5}$ Department of Biotechnology, Mizoram University, Aizawl, Mizoram 796004, India. ${ }^{6}$ DOS in Biotechnology, University of Mysore, Manasagangotri, Mysore, India. 'Botany and Microbiology Department, College of Science, King Saud University, P.O. Box. 2460, Riyadh 11451, Saudi Arabia. ${ }^{8}$ Mycology and Plant Disease Survey Department, Plant Pathology Research Institute, ARC, Giza 12511, Egypt. ${ }^{9}$ Toxicology Laboratory, Department of Zoology, Govt. Raza P.G. College, Rampur, U.P 244901, India. ${ }^{10}$ Plant Production Department, College of Food and Agricultural Sciences, King Saud University, P.O. Box. 2460, Riyadh 11451, Saudi Arabia.
Received: 30 September 2019 Accepted: 6 January 2020

Published online: 13 January 2020

\section{References}

1. Santini A, Novellino E. Nutraceuticals in hypercholesterolaemia: an overview. Br J Pharmacol. 2017;174:1450-63.

2. Anand SS, Hawkes C, De Souza RJ, Mente A, Dehghan M, Nugent R, et al. Food consumption and its impact on cardiovascular disease: importance of solutions focused on the globalized food system a report from the workshop convened by the world heart federation. J Am Coll Cardiol. 2015; 66:1590-614.

3. Dandona L. The changing patterns of cardiovascular diseases and their risk factors in the states of India: the global burden of disease study 1990-2016. Lancet Glob Health. 2018;6:e1339-51.

4. Asha B, Madhav NVS, Upadhyaya K. An huge updated review on dyslipidemia etiology with various approaches for its treatment. Pharmacophore. 2012;3:244-64.

5. Vettor R, Serra R. Management of hypercholesterolemia, appropriateness of therapeutic approaches and new drugs in patients with high cardiovascular risk. Ital J Med. 2018;12:203-12.

6. Ramkumar S, Raghunath A, Raghunath S. Statin therapy: review of safety and potential side effects. Acta Cardiol Sin. 2016;32:631-9.

7. Jain PG, Surana SJ. Hypolipidemic activity of Prosopis cineraria L (Druce) fruit extract and molecular modeling study with farnesoid $X$ receptor (FXR). Trop J Pharm Res. 2015;14:1621-8.

8. Kumar L, Prasad M, Arya D, Bhagour K. In vitro and in vivo antidiabetic activity of isolated fraction of Prosopis cineraria against streptozotocininduced experimental diabetes : a mechanistic study. Biomed Pharmacother. 2018;108:1015-21.

9. Janbaz KH, Haider S, Imran I, Zia-Ul-Haq M, De Martino L, De Feo V. Pharmacological evaluation of prosopis cineraria (L.) Druce in gastrointestinal, respiratory, and vascular disorders. Evid Based Complement Alternat Med. 2012;2012:1-7.

10. Liu Y, Singh D, Nair MG. Pods of Khejri (Prosopis cineraria) consumed as a vegetable showed functional food properties. J Funct Foods. 2012;4:116-21.

11. Zhu ZJ, Schultz AW, Wang J, Johnson CH, Yannone SM, Patti GJ, et al. Liquid chromatography quadrupole time-of-flight mass spectrometry characterization of metabolites guided by the METLIN database. Nat Protoc. 2013;8:451-60.

12. Baskaran G, Salvamani S, Ahmad SA, Shaharuddin NA, Pattiram PD, Shukor MY. HMG-CoA reductase inhibitory activity and phytocomponent investigation of Basella alba leaf extract as a treatment for hypercholesterolemia. Drug Des Devel Ther. 2015;9:509-17.

13. Lingegowsa DSC, Kumar K, Prasad AGD, MAHSA Zarei M GS. FTIR spectroscopic studies on cleome gynandra - comparative analysis of functional group before. Rom J Biophys. 2013;22:137-43.

14. Ergin G, Çağlar S, Önal A, Toker SE. Spectrophotometric determination of 3hydroxy-3-methylglutaryl coenzyme-a reductase inhibitors in pharmaceutical preparations. Turk J Chem. 2013;37:171-81.

15. Ram H, Jatwa R, Purohit A. Antiatherosclerotic and cardioprotective potential of acacia Senegal seeds in diet-induced atherosclerosis in rabbits. Biochem Res Int. 2014;2014:1-6.

16. Abell L, Levy B, Kendall E, Brodie B. A simplified method for the estimation of total cholestrol in serum and demonstration of its specificity. J Biol Chem. 1952;195:357-66.

17. Klotzsch SG, McNamara JR. Triglyceride measurements: a review of methods and interferences. Clin Chem. 1990;36:1605-13.

18. Hirano T, Nohtomi K, Koba S, Muroi A, Ito Y. A simple and precise method for measuring $\mathrm{HDL}$-cholesterol subfractions by a single precipitation followed by homogenous HDL-cholesterol assay. J Lipid Res. 2008;49:1130-6.

19. William TF, Robert IL, Donald SF. Estimation of the Concentrationof LowDensity Lipoprotein Cholesterolin Plasma, Without Use of the Preparative Ultracentrifuge. Clin Chem. 1872;18(6):499-502.

20. Trinder P. Determination of blood glucose using an oxidase-peroxidase system with a non-carcinogenic chromogen. J Clin Pathol. 1969;22:158-61.

21. Ohkawa H, Ohishi N, Yagi K. Assay for lipid peroxides in animal tissues by thiobarbituric acid reaction. Anal Biochem. 1979;95:351-8.

22. Weydert CJ, Cullen JJ. Measurement of superoxide dismutase, catalase and glutathione peroxidase in cultured cells and tissue. Nat Protoc. 2010;5:51-66.

23. Morris GM, Ruth H, Lindstrom W, Sanner MF, Belew RK, Goodsell DS, et al. Software news and updates AutoDock4 and AutoDockTools4: automated docking with selective receptor flexibility. J Comput Chem. 2009;30:2785-91. 
24. Modak M, Dixit P, Londhe J, Ghaskadbi S, Paul DT. Indian herbs and herbal drugs used for the treatment of diabetes. J Clin Biochem Nutr. 2007;40:163-73.

25. Bhadoriya SS, Mangal A, Madoriya N. Bioavailability and bioactivity enhancement of herbal drugs by " nanotechnology ": a review. J Curr Pharm Res. 2012;8:1-7.

26. Khan MY, Gupta P, Bihari B, Misra A, Pathak A, Verma VK. A review on obesity and its management. Int J Sci Eng Res. 2012;3:1-9.

27. Niimi M, Yang D, Kitajima S, Ning B, Wang C, Li S, et al. ApoE knockout rabbits: A novel model for the study of human hyperlipidemia. Atherosclerosis 2016;245:187-93.

28. Madariaga YG, Cárdenas MB, Irsula MT, Alfonso OC, Cáceres BA, Morgado EB. Assessment of four experimental models of hyperlipidemia. Lab Anim (NY). 2015:44:135-40

29. Wissler W. Animal models for hyperlipidemia-induced atherosclerosis. In: Paoletti R, et al., editors. Drugs affect lipid metab. Berlin Heidelberg: Springer-Verlag; 1987. p. 111-6.

30. Kajal A, Kishore L, Kaur N, Gollen R, Singh R. Therapeutic agents for the management of atherosclerosis from herbal sources. Beni-Suef Univ J Basic Appl Sci. 2016;5:156-69.

31. Adhikari A, Saha A, Indu R, Sur TK, Das AK. Evaluation of anti-inflammatory effect of beetroot extract in animal models. Int J Basic Clin Pharmacol. 2017; 6:2853-8.

32. Moss JWE, Ramji DP. Nutraceutical therapies for atherosclerosis. Nat Rev Cardiol. 2016;13:513-32.

33. Ram H, Purohit A, Ram H. Hypolipidemic and antiatherosclerotic effects of Prosopis cineraria bark extract in experimentally induced hyperlipidemic rabbits. Asian J Pharm Clin Res. 2016;5:106-9.

34. Feig JE. Regression of atherosclerosis: insights from animal and clinical studies. Ann Glob Heal. 2014;71:3831-40.

35. Francis AA, Pierce GN. An integrated approach for the mechanisms responsible for atherosclerotic plaque regression. Exp Clin Cardiol. 2011;16: 77-86.

36. Elshazly MB, Stegman B, Puri R. Regression of coronary atheroma with statin therapy. Curr Opin Endocrinol Diabetes Obes. 2016;23:131-7.

37. Islam B, Sharma C, Adem A, Aburawi E, Ojha S. Insight into the mechanism of polyphenols on the activity of HMGR by molecular docking. Drug Des Devel Ther. 2015:9:4943-51.

38. Suganya S, Nandagopal B, Anbarasu A. Natural inhibitors of HMG-CoA reductase - an Insilico approach through molecular docking and simulation studies. J Cell Biochem. 2017;118:52-7.

39. Gholamhoseinian A, Shahouzehi B, Sharifi-Far F. Inhibitory activity of some plant methanol extracts on 3-Hydroxy-3-Methylglutaryl coenzyme a reductase. Int J Pharmacol. 2010;6:705-11.

40. Hwang KA, Hwang YJ, Song J. Cholesterol-lowering effect of Aralia elata (Miq.) Seem via the activation of SREBP-2 and the LDL receptor. J Chinese Med Assoc. 2017:80:630-5

41. Yadav E, Singh D, Yadav P, Verma A. Comparative evaluation of Prosopis cineraria (L.) druce and its $\mathrm{ZnO}$ nanoparticles on scopolamine induced amnesia. Front Pharmacol. 2018;9:1-18.

42. Yang $X$, Li Y, Li Y, Ren X, Zhang X, Hu D, et al. Oxidative stress-mediated atherosclerosis: mechanisms and therapies. Front Physiol. 2017;8:1-16.

43. Park SH, Hun Paek J, Shin D, Lee JY, Lim SS, Kang YH. Purple perilla extracts with a-asarone enhance cholesterol efflux from oxidized LDL-exposed macrophages. Int J Mol Med. 2015;35:957-65.

44. Manikandan SDR. Antioxidant property of alpha-asarone against noisestress-induced changes in different regions of rat brain. Pharmacol Res. 2005:52:467-74

45. Higashi. Endothelial function in cardiovascular diseases. Circ J. 2009;73:411-8.

46. Olorunnisola OS, Bradley G, Afolayan AJ. Protective effect of T. violacea rhizome extract against hypercholesterolemia-induced oxidative stress in wistar rats. Molecules. 2012;17:6033-45.

47. Serairi-Beji R, Aidi Wannes W, Hamdi A, Tej R, Ksouri R, Saidani-Tounsi M, et al. Antioxidant and hepatoprotective effects of Asparagus albus leaves in carbon tetrachloride-induced liver injury rats. J Food Biochem. 2018;42:1-11.

\section{Publisher's Note}

Springer Nature remains neutral with regard to jurisdictional claims in published maps and institutional affiliations.

Ready to submit your research? Choose BMC and benefit from:

- fast, convenient online submission

- thorough peer review by experienced researchers in your field

- rapid publication on acceptance

- support for research data, including large and complex data types

- gold Open Access which fosters wider collaboration and increased citations

- maximum visibility for your research: over $100 \mathrm{M}$ website views per year

At $\mathrm{BMC}$, research is always in progress.

Learn more biomedcentral.com/submissions 